\title{
A INGLATERRA E OS VINHOS PENINSULARES (SÉC. S XV A XVIII)
}

\author{
António Barros Cardoso \\ UNIVERSIDAD DE OPORTO
}

\section{RESUMEN}

Este artículo analiza en perspectiva comparada un aspecto esencial de la vitivinicultura de la Península Ibérica entre los siglos XV y XVIII: el papel desempeñado por los británicos en la producción de vinos, principalmente de los generosos y licorosos de Oporto y el Marco del Jerez. Y lo hace considerando a los británicos en su triple condición de consumidores, comerciantes y vitivinicultores.

Palabras Clave: británicos, comercio, Jerez, Oporto, vitivinicultura.

\section{ABSTRACT}

This article studies an essential aspect of grape and wine-growing in the Iberian peninsula between the $15^{\text {th }}$ and $18^{\text {th }}$ centuries from a comparative view: the role carried out by the British in the production of wines, mainly the full-bodied and strong ones from Port and the Jerez District. The study takes into account the three positions of the British: as consumers, merchants and grape and wine-growers.

Key Words: The British, Britons, trade, Jerez, Port, grape and wine-growing.

Torna-se incontornável falar em vinhos licorosos sem fazer referência ao papel desempenhado pelos britânicos na sua preparação. É conhecida a importância dos mercadores ingleses no desenvolvimento do comércio da maioria dos vinhos licorosos que o mundo hoje conhece e essa importância deixa antever que também ao nível das técnicas de vinificação de tais vinhos, eles terão tido forte influência, quanto mais não seja pela necessidade de irem ao encontro do gosto e das preferências do consumidor final ${ }^{1}$.

1 De facto, os britânicos desempenharam, ao longo dos séculos XVII e XVIII, importante papel no trato dos vinhos licorosos. Consequentemente a sua intervenção na evolução das técnicas de vinificar tais vinhos deve ser equacionada quanto mais não seja pelo facto de que qualquer comerciante, independentemente do produto com que se ocupa, procurar ir ao encontro das solicitações do mercado, adaptando o seu produto à demanda, ontem como hoje. 
No caso dos vinhos do Porto, os ingleses que cedo se instalaram na capital do Norte de Portugal. Aí tiveram papel preponderante no comércio. De facto, ao longo de toda a primeira metade do século XVIII, época de arranque do trato internacional destes vinhos, foram eles que fizeram entrar na cidade a maior quantidade de pipas oriundas do Douro. A sua exportação foi dominada pelas casas comerciais que constituíram e o seu papel no mercado local não foi despiciendo já que, todos os anos, boa parte dos vinhos que compravam, cuja qualidade não servia para exportação, era colocada nas tabernas da cidade. Por isso, pensamos que lhes coube também um papel de primeiro plano na caminhada experimental que conduziu aos "Vinhos do Porto"”.

\section{VINHO DE MISSA E VINHO PARA CONSUMO NA INGLATERRA MEDIEVAL}

É muito longínquo o interesse da Inglaterra pelo vinho. Tal interesse remonta já ao período da ocupação romana da Bretanha. Muito embora cerca de 500 a. C. já se plantassem os primeiros vinhedos em Marselha, Portugal e Espanha, só muito depois o vinho chegou a Inglaterra. Datam do século I a. C., as primeiras evidências da presença do vinho nas Ilhas Britânicas $^{3}$. Foi nessa altura que, muito provavelmente, tiveram lugar as primeiras importações de vinhos. De forma mais regular, a Inglaterra e Irlanda, importaram vinhos a partir do séc. VI e estas importações estão bem documentadas a partir do século X. A proválo, o facto de o vinho ser incluído na dieta dos monges beneditinos que então habitaram os seus mosteiros.

Após os romanos terem saído da Bretanha e mesmo antes da conquista Normanda, era já tradicional beber vinho em Inglaterra. O carácter religioso da bebida era a principal razão com eco junto das comunidades cristãs. Afinal, celebrar a Missa sempre implicou o uso do vinho, daí a importância do produto enquanto necessidade quase universal. Por isso, é certo que foram também as instituições religiosas inglesas as primeiras a responsabilizar-se pelo início do plantio de vinhas nas suas terras. De resto, sabe-se que até dispunham dos meios materiais e humanos par o fazer, a avaliar pelas informações do Domesday Book, que menciona 38 vinhedos na sua área jurisdicional. Contudo, tudo indica que as primeiras vindimas inglesas não ficaram famosas nem na abundância, nem na qualidade do vinho produzido. Tratou-se de pequenas produções que encorajaram os seus promotores a continuar, mas apenas para satisfizerem as necessidades eclesiásticas. Neste contexto percebe-se bem porque no tempo de Carlos Magno, a Inglaterra já importava vinhos da Ille de France, da Burgonha e do Loire ${ }^{4}$. De resto, antes da saga Normanda, o vinho consumido pelos ingleses era já conhecido em variedades por eles classificadas de: "clear, strong, austere, soft, sweet, etc." 5 .

Foi Eduardo o Confessor quem concedeu aos estrangeiros a liberdade trazerem à GrãBretanha os seus vinhos. Após a conquista Normanda e reconhecido como rei pelos dois

\footnotetext{
2 Entenda-se aqui por vinhos do Porto aqueles que começaram a correr mundo sob esta denominação de origem e cujas técnicas de vinificação foram sendo apuradas ao ponto de originarem o produto hoje comercializado em todo o mundo sob a marca "Porto".

FRANCIS, Alan Davis: The Wine Trade, London, 1972, p. 1.

FRANCIS, Alan Davis: The Wine Trade, London, 1972, pp. 3-4.

SIMON, André. L.: Wine and the Wine Trade, 1934, London, p. 1.
} 
lados do Canal da Mancha, o comércio entre o Continente e a Inglaterra conheceu um forte impulso. O vinho, assume já por essa altura lugar de primeira grandeza nessas trocas comerciais. Os mercadores de vinho de Ruão, construíram mesmo no coração da cidade de Londres, na desembocadura do Wall Brook, um atracadouro próprio para a descarga do seu vinho ${ }^{6}$. Na realidade, os normandos estavam muito mais familiarizados com a arte do vinho que os anglo-saxões, o que lhes deu um papel importante no reforço do consumo da bebida nas Ilhas Britânicas. De resto, em boa parte foram os responsáveis pelo acentuar da conotação aristocrática de consumir vinho, conhecida entre os ingleses.

O casamento entre Leonor da Aquitânia e Henrique Plantageneta, Duque de Anjou e da Normandia (séc. XII), traduziu-se num novo alento para as trocas comerciais entre os dois lados do Canal da Mancha. Por essa altura, o vinho bordalês começa a granjear fama nas Ilhas Britânicas, adquirindo os mercadores gascões, durante algum tempo, o monopólio do comércio de vinhos nas Ilhas Britânicas ${ }^{7}$. Por essa altura, navios carregados com cascos de vinho chegavam a Inglaterra, oriundos directamente de Bordéus, da foz do Loire e de La Rochelle. Londres era o principal porto de entrada desses vinhos, embora Sandwich e Bristol também recebessem alguns cascos. O depósito real de vinhos situavase então em Southampton ${ }^{8}$.

Este trato permaneceu próspero até 1335. Calcula-se que nas primeiras três décadas do século XIV tenham entrado nos portos ingleses 82.710 pipas de vinho. Destas, 13.000 entraram ao abrigo do privilégio fiscal de que gozavam os cidadãos de Bordéus. De qualquer forma, a coroa britânica recebia largos proventos alfandegários deste intenso trato 9 .

De 1335 em diante, Eduardo III proibiu a exportação de moeda. Em consequência, comerciantes bordaleses começam a procurar novos mercados. O norte da Europa foi uma dos alvos. De facto, Hamburgo já liderava comercialmente uma galáxia de portos marítimos que serviam as zonas da Europa mais a Norte, dando corpo à conhecida Liga Hansiática. Foi precisamente esse um dos mercados alvo dos mercadores de vinho de Bordéus. Na tentativa de aí colocarem os seus vinhos, quase abandonaram por completo o tradicional mercado britânico. Entre 1335 e 1368, calcula-se que as importações anuais de vinho de Bordéus pela Inglaterra não ultrapassaram as 30.000 pipas, valor que, depois de declarada a guerra entre a França e a Inglaterra (1369), desceu para as 11.000 pipas $^{10}$.

A Inglaterra não podia prescindir do vinho francês. Logo depois de 1368, os ingleses começam a enviar a Bordéus navios e mercadores para adquirirem largas partidas de vinhos, dando início à construção do seu império comercial marítimo em torno do comércio vinícola, concorrendo com gascões, flamengos, genoveses e germânicos ${ }^{11}$.

O bordalês adquiriu fama e proveito comercial entre os ingleses. O comércio dos vinhos com a Aquitânia, passou a assumir forma regular e organizada. Nos finais de todos os Outonos saíam dos portos de Inglaterra grande número de barcos cujo destino era o outro lado da Mancha. Pouco depois (antes do Natal) regressavam às Ilhas Britânicas com car-

TREVEYLAN, G.M. : História Concisa de Inglaterra, Mem Martins, 1990, I, p. 99.

Em 1212, quando o Rei João comprou 358 cascos de vinho, a percentagem do vinho Gascão, rondava os $75 \%$.

SIMON, André. L. : Wine and the Wine Trade, 1934, London, p. 2

FRANCIS, Alan Davis: The Wine Trade, London, 1972, p. 7

FRANCIS, Alan Davis: The Wine Trade, London, 1972, pp. 11-12

FRANCIS, Alan Davis: The Wine Trade, London, 1972, p. 12

SIMON, André. L: Wine and the Wine Trade, 1934, London, p. 3. 
ga de vinhos novos. Esse regresso era mesmo organizado em "comboio", estratégia que adoptaram como defesa contra eventuais agressores durante as viagens de retorno a Inglaterra.

À semelhança do que sucedeu na Península Ibérica, os vinhos comercializados em Inglaterra, fosse por ingleses, fosse por mercadores estrangeiros, constituiu desde cedo uma importante fonte de receita fiscal. No caso britânico, os navios que descarregavam vinhos nos seus portos, reservavam dois cascos por navio, ou o seu equivalente em dinheiro para a coroa britânica. Os retalhistas que o vendiam atavernado, estavam ainda sujeitos a impostos municipais e obrigados a cumprir as posturas de preços. Se ultrapassassem os preços máximos fixados para venda ao consumidor, eram alvo de punições. Eram ainda obrigados ao respeito pelas qualidades, obedecendo a normas regulamentadoras das lotações de vinhos de tipos diferenciados ${ }^{12}$.

\section{O VINHO DE BORDÉUS EM INGLATERRA E A CONCORRÊNCIA (SÉC. XIV)}

A ligação comercial anglo-bordalesa fez com que, na segunda metade do século XIV, o mercado britânico estivesse já totalmente invadido pelos vinhos de Bordéus que encontravam uma ligeira concorrência movida por outros vinhos franceses. Apesar disso, reputados vinhos provenientes da Alemanha eram já nessa altura bebidos em Inglaterra. Aí eram apreciados sobretudo vinhos doces, produzidos por métodos tradicionais e por vinhateiros que tiravam partido de zonas climáticas específicas para a sua produção. Vinhos de igual natureza provenientes do Levante também se bebiam. Os malvazia eram os mais divulgados sob a designação de sweet wine $^{13} \mathrm{e}$ aceitase que tenham sido estas variedades de vinho a abrir as portas à penetração dos primeiros vinhos portugueses e espanhóis no gosto dos apreciadores britânicos.

De facto, ao longo de todo o século XIV, os vinhos doces tornaram-se muito populares em Inglaterra, embora fossem aí conhecidos um pouco antes. A título de exemplo, citamos o caso do Arcebispo de York que, em 1295, fez uma compra de vinhos malvazia ${ }^{14}$. Pela mesma altura, este mesmo prelado adquiriu algum $O$ sey, designação pela qual foram conhecidos mais tarde os vinhos peninsulares em Inglaterra, provavelmente para designar vinhos dos arredores de Lisboa e Setúbal. Certo é que, embora não tenha ficado registo para o sustentar documentalmente, a remessa de vinhos de Portugal para Inglaterra parece ter sido uma realidade ainda no século XIV e o Osey um vinho muito divulgado nas Ilhas Britânicas desse tempo ${ }^{15}$. Igualmente importante nos parece uma referência a outra designação de origem portuguesa para vinhos, mencionada por Shakespeare: Charneca, termo que aparece a identificar os arredores de várias cidades e vilas portuguesas, facto que torna difícil admitirse, sem mais, tratarse de vinho de Colares ${ }^{16}$. O que é facto é que em

12 Sobre o preço dos vinhos em Inglaterra e a sua evolução até ao séc. XVIII, ver SIMON, André. L: Wine and the Wine Trade, 1934, London, pp. 7-9

FRANCIS, Alan Davis: The Wine Trade, London, 1972, p. 15

FRANCIS, Alan Davis: The Wine Trade, London, 1972, p. 18

15 Os monges de Batle compravam-no usualmente em Sandwich e Chaucer e mais tarde Shakespeare, menciona-o nos seus escritos. FRANCIS, Alan Davis: The Wine Trade, London, 1972, p. 18

16 FRANCIS, Alan Davis: The Wine Trade, London, 1972, p. 18 
tempos medievais, os ingleses já se interessavam pelos vinhos peninsulares e, entre estes, os vinhos doces despertavam já o seu interesse.

\section{OS VINHOS DOCES NA INGLATERRA DOS ALVORES DA ÉPOCA MODERNA}

Estas notícias, por muito interesse que possam revestir, demonstram sobretudo que estamos ainda muito longe dos primeiros vestígios que, com solidez, permitam levantar a ponta do véu sobre a origem dos vinhos que mais tarde acabaram por marcar a presença britânica nos principais portos vinícolas peninsulares.

No caso dos vinhos do Porto (Douro), somente temos notícias que permitem situar o conhecimento destes vinhos em Inglaterra em cronologias que apontam para a segunda metade do século XV. Tudo o indica, foi o checo Barão de Rozmital, quem aí deles falou pela primeira vez. Em 1460, visitou extensas áreas da Europa e nesse tempo passeou no Alto-Douro, entrando pela fronteira espanhola e caminhando por terras do Freixo a Torre de Moncorvo. Deixou impressionante relato de lugares pejados de bandidos, onde se contam terríficas lendas que incluem dragões, certamente impressionado com a monumentalidade e o exotismo da paisagem que viu abrir-se-lhe diante dos olhos (o Douro). No seu relato, também se referiu ao facto de que, no sopé das montanhas, havia vinha, amendoeiras e figueiras. Designou o vinho que então aí se produzia como "Vinho de Grécia" e adiantou que era feito esmagando uvas tintas maduras como passas ${ }^{17}$. Estamos em presença de uma notícia que se refere a vinho doce e é de admitir como verosímil que algum deste vinho tenha sido apreciado nas mesas da aristocracia britânica de então. A sua pequena expressão quantitativa não fez chegar até nós notícias abundantes sobre ele.

Certa é a chegada de outros vinhos portugueses a Inglaterra. Em 1465/66 sabe-se terem sido descarregados nos cais de Bristol, seis navios que transportaram 500 pipas de vinho de Lisboa $^{18}$.

Ao longo do século XVI, manteve-se a presença preferencial dos vinhos de Bordéus no mercado britânico. Maugrado substanciais mudanças operadas pelos Tudor e pelos Stuarts na forma de cobrança dos direitos de importação sobre os vinhos continentais, as importações de vinho continental passaram a ser autorizadas através de licenças individuais concedidas aos mercadores. Em contrapartida, exigia-se-lhes pagamentos adiantados dos direitos dos vinhos que se comprometiam a fazer entrar nos portos ingleses. Estas medidas tiveram como maior consequência o afastamento dos pequenos comerciantes do negócio, já que as referidas licenças eram mais facilmente atribuídas para a importação de grandes quantidades de vinho. Quem vendia vinho nas tabernas, teve de seguir idêntico procedimento, adiantando algum dinheiro no acto das encomendas dos seus vinhos, que, naturalmente, diminuíram em quantidade.

FRANCIS, Alan Davis: The Wine Trade, London, 1972, p. 19

18 FRANCIS, Alan Davis: The Wine Trade, London, 1972, p. 19 


\section{A SELECÇÃO INGLESA E OS VINHOS DOCES DA ANDALUZIA (SÉC.S XV- XVII)}

A guerra das Rosas contribuiu para diminuir o número de elementos da nobreza inglesa e, por consequência, o consumo de vinhos nas Ilhas Britânicas. Contudo, a distinção social de beber vinho, marca da aristocracia britânica, levou a que, embaixadores, juízes, bispos, membros dos conselhos privados e da corte, recorressem a mecanismos de isenção de direitos alfandegários sobre as quantidades que necessitassem para gasto de suas casas, o que compensou as quebras de consumo registadas ${ }^{19}$.

Assim, para além dos vinhos de Bordéus, entraram em Inglaterra durante os séculos XV e XVI os vinhos de Poitou, saídos sobretudo pelo porto de La Rochelle. De resto, beber estes vinhos não era novidade para os ingleses já que, através da captura de navios ao largo do porto francês, cedo começaram a tomar contacto com eles ${ }^{20}$. Henrique VII promoveu o seu consumo ao emitir muitas licenças para, de forma legal, ser possível importar vinho de Poitou através do porto de La Rochelle.

Este porto francês, um século depois, ou seja, no decurso dos últimos dez anos do reinado da Rainha Elisabeth, fez entrar em Inglaterra cerca de 6.000 toneis de vinho. A avaliar pelo preço, a sua qualidade não seria a de um vinho superior. De facto, custava cerca de metade do preço de outros vinhos franceses, o que leva a crer que o vinho de Poitou tenha perdido popularidade entre os britânicos.

Os vinhos de Nantes, Anjou e Orleães, também entravam nas Ilhas Britânicas, embora apenas ocasionalmente. O porto de Ruão, o mais importante no tráfego comercial entre a França e a Inglaterra, teve expressão de relevo também no trato destes vinhos. A partir dele estabeleciam-se comunicações regulares com os portos ingleses de Londres, Southampton, Hull, Exeter, Newcastle-on-Tyne, Bristol, Poole, Malden, Lynn, Hartlepool, bem como com outros portos que constituíram mais tarde destino para os vinhos do Douro, particularmente no decurso de toda a primeira metade do século XVIII.

As Ilhas Britânicas bebiam também algum vinho de várias zonas da Normandia: Beaune, Auxerre e Burgonha. Entre 1559 e 1565, entraram nas Ilhas Britânicas 7576 toneis destes vinhos através de Rouen e Calais ${ }^{21}$. Ao mesmo tempo, o alto preço dos vinhos da Champagne, impediu a sua franca penetração no mercado inglês durante o século XVI. Verdadeiramente, os ingleses só passaram a interessar-se por estes vinhos nos finais do século seguinte.

Os vinhos alemães continuaram a ser apreciados pela Inglaterra dos séculos XV e XVI. Os da Alsácia e do Alto Reno, sobretudo os primeiros, eram, pela sua fortaleza, considerada os melhores. Bruges, durante muito tempo o principal porto da Baixa Alemanha, serviu de porta de saída a estes vinhos ${ }^{22}$.

Os vinhos austríacos e húngaros também não eram totalmente desconhecidos na Inglaterra de finais do século XVI, os. Os Tokay ${ }^{23}$ da Hungria constituíram lucrativo recur-

FRANCIS, Alan Davis: The Wine Trade, London, 1972, p. 26

20 Em 1402, 200 toneis de vinho de La Rochelle foram descarregados na ilha de Wight. Logo no ano seguinte 79 toneis foram tomados de vários navios e rumaram a Weymouth. SIMON, André L. : The History of the wine trade in England, III vol., London, 1964, vol. II, p. 194.

21 SIMON, André L.: The History of the wine trade in England, III vol., 1964, London, vol. II, pp. 198-199

22 SIMON, André L: The History of the wine trade in England, III vol., 1964, London, vol. II, pp. 201-202

23 O vinho Tokay, é considerado não um vinho mas o "príncipe dos licores". Trata-se de um vinho muito licoroso, cuja produção remonta ao período da ocupação Romana. A sua produção é limitada e a técnica de fabrico assenta 
so comercial nas trocas com os países do Norte da Europa. Da Áustria, eram já conhecidos e apreciados em Inglaterra os Riboldi, denominação fixada na Inglaterra do século XIX na expressão Rybole ${ }^{24}$.

E dos vinhos espanhóis? Que notícias há? Também entraram na Inglaterra dos tempos medievais. Nesses tempos mais recuados, Porto de Santa Maria e Cádiz eram já os locais de embarque de vinhos a caminho de Inglaterra. Nos alvores do século XVI (1517), o Duque de Medina Sidonia ao regular o comércio de vinho Jerezano consagrou já uma especial protecção a todos os homens de negócio britânicos que se deslocassem a Sevilha, Cádiz e Jerez a fim de adquirirem vinhos, sinal inequívoco do interesse dos ingleses pelos vinhos do Sul de Espanha. De resto, sabe-se que era anterior a essa data o emprego da designação Sack ou Seck para identificar estes vinhos que não seriam tão doces como outros vinhos peninsulares, alguns de proveniência Italiana ou do Levante. Contudo, a expressão Sack não aparece em nenhum diploma de fixação de preços de venda anterior a 1532, altura em que, num documento de ordem de venda, são assim designados. As abundantes notícias sobre a entrada destes vinhos em Inglaterra ao longo de todo o século XVI, mostram a sua popularidade entre os britânicos já nessa época. Originalmente, tratava-se de um vinho de cor âmbar, carregado exclusivamente no Sul de Espanha e ocasionalmente adocicado com a junção de melaço ou açúcar, de forma a adquirir o gosto predominante em Inglaterra para os vinhos doces. Sabe-se também que a sua popularidade fez surgir imitações deste vinho noutras partes de Espanha, nas ilhas Canárias, no Sul de França e mesmo em Portugal, imitações cuja qualidade ficava muito aquém da bebida genuína ${ }^{25}$.

Nos finais do século XVI, o interesse dos britânicos pelos vinhos da Andaluzia fez com que, nessa altura, companhias comerciais inglesas se instalassem em Cádiz, Porto de Santa Maria e Sanlucar de Barrameda. Um documento enviado ao Cabido Jerezano datado de 3 de Setembro de 1582, em que o cônsul britânico em nome de todos os mercadores ingleses implicados no trato de vinhos com a cidade de Jerez se queixava da medida das pipas que sempre haviam comportado 30 arrobas de vinho, mas que, nessa altura, se apresentavam diminuídas entre 2 a 2,5 arrobas de vinho, deixou nota da existência dessas casas comerciais inglesas estabelecidas nas "cidades do vinho" da Espanha do $\mathrm{Sul}^{26}$.

Embora conhecidos desde o período Romano, os vinhos de Tarragona, não aparecem sob esta designação no mercado inglês quinhentista. Mas o mesmo não se passa com os vinhos do Norte de Espanha, nomeadamente os de La Rioja, Logrono e Navarette, que entraram nas Ilhas Britânicas sob a designação de Ryvere Wines. Os vinhos galegos das margens do rio Minho, abundantes no século XVI, também não eram muito apreciados em Inglaterra. Aparecem aí de forma irregular, mais em resultado da captura de algum navio com carga desses vinhos do que de um circuito comercial montado em torno do seu tra-

essencialmente na longa vindima dos bagos que vão sendo colhidos na medida exacta da sua maturação ideal, muito próxima das uvas passas. Sobre este vinho ver SIMON, André L.: Wines of the World, London, New York, Toronto, 1967, Sydney, pp. 577-580

24 SIMON, André L. The History of the wine trade in England, III vol., 1964, London, vol. II, p. 206.

25 Sherry Sack, Canary Sack, Madeira Sack, Dry Sack e Sweet Sach, foram expressões que designaram vinhos deste tipo. . SIMON, André L.:The History of the wine trade in England, III vol., 1964, London, vol. II, p. 210.

26 GONZÁLEZ GORDON, Manuel Maria, Marquez de Bonanza: Jerez-Xerez-Sherish. Noticias sobre el orígen de esta ciudad su historia y su vino, 1970, Jerez de La Frontera, pp. 103-104 
to ${ }^{27}$. Já os vinhos produzidos nas Ilhas Canárias, onde a vinha foi ocupando espaço agrícola ao longo de todo o século XVI e onde se produziram vinhos cujas características os tornaram semelhantes aos do Jerez, embora mais adocicados, foram comercializados pelos ingleses desde 1598. De facto, sabe-se que nessa data chegaram às ilhas os primeiros mercadores britânicos interessados na compra de tais vinhos ${ }^{28}$.

Equanto a vinhos portugueses? Ao longo do século XVI, Portugal andaria, em termos de evolução do plantio da vinha, não muito longe da Espanha ou de qualquer outro país produtor. Navios carregados com vinhos portugueses cruzavam nessa altura todos os mares e em todas as direcções conhecidas. Por isso, pensa-se que os vinhos nacionais não seriam totalmente desconhecidos nas Ilhas Britânicas. De resto, são abundantes os testemunhos que mostram o contacto dos britânicos com os nossos vinhos do Porto e de outras regiões produtoras de Portugal ${ }^{29}$. Não se pode é falar de um comércio regular de vinhos portugueses no mercado inglês do século XVI, semelhante ao que, se estabeleceu nos séculos seguintes em torno dos vinhos do Alto-Douro.

\section{O VINHO BEBIDA DE ELEIÇÃO NA INGLATERRA DO SÉCULO XVII}

Embora possa parecer exagero falar-se do triunfo do vinho nas Ilhas Britânicas ao longo do século XVII, a verdade é que, nessa época, se desenvolve forte competição no mundo comercial dos vinhos destinados ao abastecimento do mercado inglês, umas vezes movida por razões meramente comerciais mas, muitas vezes, por motivos de estratégia política e militar. Por isso, advogamos algum investimento da investigação fundamental na história do comércio internacional do vinho neste período, assente em documentação diplomática. Estamos convictos de que ajudará a compreender melhor o quadro económico do trato vinícola.

Os primeiros anos do reinado de Jaime I (1603-1625) foram marcados por uma liberalização do comércio de vinhos. Apesar disso o vinho francês ocupava o primeiro lugar destacado no mercado britânico. Para tanto, muito contribuíram os monopólios do trato do vinho bordalês. Quando em 1610, faleceu Lord High Admiral, surgiu a oportunidade de abertura a novos mercados, concretizada no estabelecimento de um acordo comercial com Veneza para o trato dos vinhos. No entanto, este viria a ser irremediavelmente comprometido pela eclosão da Guerra dos Trinta Anos (1618), altura em que muitos vinhedos do Reno foram destruídos e em que passou a ser encorajada a produção e o consumo da cerveja em substituição do vinho ${ }^{30}$. De facto, até 1624, ano em que o Parlamento britânico decretou a abolição de todos os privilégios que na prática se traduziam na constituição de monopólios comerciais no tocante ao comércio de vinhos para Inglaterra, Jaime I manteve

\footnotetext{
SIMON, André L. : The History of the wine trade in England, III vol., 1964, London, vol. II, p. 212

SIMON, André L. :The History of the wine trade in England, III vol., 1964, London, vol. II, p. 213.

Testemunhos que dão uma noção de que entre 1402 e os finais do século XVI, muitos contactos houve entre os vinhos de Portugal e os ingleses. De facto, inúmeros navios portugueses carregados com vinhos foram interceptados nos mares. Por outro lado, algumas compras de vinhos foram efectuadas por mercadores britânicos em Portugal. Durante o período filipino, algumas embarcações portuguesas com vinhos destinados à armada de Ferrol, caíram também nas mãos dos britânicos. SIMON, André L.: The History of the wine trade in England, III vol., 1964 London, vol. II, pp. 214-216

30 FRANCIS, Alan Davis: The Wine Trade, London, 1972, p. 47
} 
a concessão de tais licenças. Elas garantiam-lhe rendimentos fiscais com carácter certo e permanente, já que esses tributos eram previamente calculados ${ }^{31}$.

Como já referimos, durante o reinado de Jaime I manteve-se a predilecção pelo consumo de vinhos provenientes de Bordéus. Todos os anos, na época que antecedia as vindimas na região da Aquitânia, um emissário britânico dirigia-se à região vinícola francesa a fim de adquirir vinhos para abastecimento da corte inglesa ${ }^{32}$. No entanto, no mercado londrino, a corte já comprava, embora ocasionalmente, alguma quantidade de vinhos doces "sweet wines" e vinho "sack". De resto, Jaime I foi o primeiro monarca a mandar servir este tipo de vinhos à mesa da corte inglesa ${ }^{33}$.

Já vimos que estas qualidades de vinho correspondiam a vinhos espanhóis que se popularizaram na Inglaterra do século XVI. A partir do início da Guerra com a França (1624) foi temporariamente interdita a importação de vinhos desta nacionalidade e outras mercadorias francesas, mesmo que em navios estrangeiros ${ }^{34}$. Apesar disso, face à dependência inglesa relativamente ao mercado francês no que toca ao abastecimento vinícola, a Inglaterra concedeu autorizações especiais para a entrada de vinhos de França nos seus portos, embora carregados em navios estrangeiros. Por isso, navios alemães e outros, pertencentes a mercadores ingleses radicados em Londres, continuaram a transportar vinhos rumo à Inglaterra, embora se conheça um influxo desse movimento comercial, particularmente depois de Dezembro de 1626, altura em que em Bordéus, 200 barcos ingleses e escoceses carregados de vinhos foram aprisionados em pleno porto ${ }^{35}$.

Certo é que a concorrência movida por outros vinhos aos vinhos de Bordéus em Inglaterra, não se fez esperar. Os vinhos espanhóis e mesmo franceses de outras regiões começaram a ocupar algum espaço dos vinhos de Bordéus. O porto de La Rochelle, servia de entreposto aos Haut Brion ${ }^{36}$, bem como aos vinhos brancos produzidos na região, muitos anos antes de os vinhos verdes portugueses do Minho entrarem naquele mercado. Este porto comercializava com a Irlanda e era base de muitos navios de pesca da Terra Nova que também estabeleciam contactos com Cádiz, Lisboa, Porto, Madeira e Açores. Na viagem de retorno desses portos, depois de venderem o peixe que transportavam, carregavam vinhos para Inglaterra ${ }^{37}$. Destaque ainda para os vinhos da região do Loire que também atingiam as costas Inglesas a partir do Porto de Nantes.

De entre os vinhos espanhóis que concorriam com os bordaleses, o mais popular era o "Sack". Já durante o reinado de Henrique VIII, algum deste vinho entrava como "vinho doce", embora, como já referimos, não constasse dos registos de fixação de preços nem das tabelas alfandegárias. De resto, esta designação é em si mesma difícil de definir. Parece corresponder ao gosto inglês por vinhos fortes e doces, como os "sherry" de onde teriam a sua base. Contudo, são definidos como vinhos inferiores aos das Canárias. Estes eram usados nesta altura como medicamento para fortalecer o estômago e por isso bebidos em

SIMON, André L. :The History of the wine trade in England, III vol., 1964, London, vol. III, p. 6

SIMON, André L. :The History of the wine trade in England, III vol., 1964, London, vol. III, p. 12

SIMON, André L. :The History of the wine trade in England, III vol., 1964, London, vol. III, p. 13

FRANCIS, Alan Davis: The Wine Trade, London, 1972, p. 47

SIMON, André L. :The History of the wine trade in England, III vol., 1964, London, vol. III, pp. 28

Vinhos tintos da região de Pessac, hoje com a denominação de origem controlada "Graves". SIMON, André: Wines

of the World, London, New York, Toronto, 1967, Sydney, p. 47

FRANCIS, Alan Davis: The Wine Trade, London, 1972, p. 49 
pequenos cálices ${ }^{38}$. Por essa mesma altura competiam já com eles os vinhos da Madeira ${ }^{39}$. Porém, a avaliar pelos preços dos vinhos praticados na Inglaterra de 1632, nenhum dos citados estava em posição de ocupar o lugar dos vinhos de Bordéus já que, os vinhos da cidade da Foz do Garonne custavam 18 libras por tonel. A 15 libras por tonel vendiam-se os outros vinhos franceses de menor qualidade, exportados através de La Rochelle. Os espanhóis das Canárias e de Alicante, os Moscateis, "saks", Málagas ou sherrys vendiamse a 16 libras por tonel.

Fica-nos a impressão de que, apesar da guerra, nestes primeiros anos do século XVII, os vinhos de Bordéus e mesmo os de menor qualidade, mas produzidos em França, continuaram a ser consumidos e apreciados em Inglaterra como vinhos de mesa. Em paralelo, ganharam forte expressão no gosto dos britânicos os "sack" designação que parece corresponder a vinhos espanhóis e portugueses, fortes e doces "sweet wines", assim classificados oficialmente alguns anos antes de 1624, quando os farmacêuticos ingleses entraram em disputa com destiladores, merceeiros e negociantes de vinhos, por estes venderem licores e tónicos como drogas medicinais ${ }^{40}$. É tradição dizer-se que foi no âmbito da venda e utilização destas mesinhas, porto a porto, que pequenas quantidades do vinho forte do Douro, chegaram a Inglaterra como produto médico, muito antes da entrada triunfante dos vinhos do porto no mercado inglês ${ }^{41}$.

Entre 1632 e 1639, assiste-se entre os britânicos à afirmação e vulgarização do consumo de vinhos peninsulares fortes e doces. A própria subida dos preços registada neste intervalo parece confirmálo:

\begin{tabular}{|l|c|c|c|c|}
\hline \multicolumn{5}{|c|}{ Preço dos vinhos em Inglaterra } \\
\hline \multicolumn{1}{|c|}{ Qualidade } & $\mathbf{1 6 3 2}$ & $\mathbf{1 6 3 5}$ & $\mathbf{1 6 3 7}$ & $\mathbf{1 6 3 9}$ \\
\hline $\begin{array}{l}\text { Canárias, Muscatel and } \\
\text { Alicante }\end{array}$ & 16 libras & 17 libras & 18 libras & 19 libras \\
\hline Sacks e Malagas & 13 libras & 15 libras & 16 libras & 17 libras \\
\hline $\begin{array}{l}\text { Gascões e outros vinhos } \\
\text { franceses }\end{array}$ & 18 libras & 18 libras & 18 libras & 19 libras \\
\hline La Rochelle & 15 libras & 15 libras & 15 libras & 16 libras \\
\hline
\end{tabular}

De facto, muito embora em 1639 se registe uma ligeira subida do preço dos vinhos franceses, os vinhos doces e fortes da Península e das Canárias mostram subidas mais acentuadas.

Em 1641, o Parlamento aumentou em duas libras por tonel o imposto extraordinário sobre os vinhos. Nessa altura, muitos vendedores de vinho foram acusados de efectuarem falsificações e várias misturas nos seus armazéns, adicionando aos vinhos açúcar e figos

3 Por vezes designado "sweet sack" ou "secke" esta expressão parece querer definir vinhos secos. Contudo ela pode também querer significar vinho de "saca", quer dizer, vinho sacado de um porto de mar visitado por contrapartida da entrega de outras mercadorias. "Sack-boats" era a designação que colhiam pequenas embarcações que faziam o transporte de peixe para a Península. Também daí podiam ter colhido o nome estes vinhos. FRANCIS, Alan Davis: The Wine Trade, London, 1972, pp. 50-51

39 FRANCIS, Alan Davis: The Wine Trade, London, 1972, p. 52

40 FRANCIS, Alan Davis: The Wine Trade, London, 1972, pp. 54-55

${ }^{41}$ FRANCIS, Alan Davis: The Wine Trade, London, 1972, p. 55 
secos, uvas bravas, amoras, alumen, madeira de pinho, serradura de madeira de Chipre, sumo de lima com açúcar, cidra, leite etc..$^{42}$.

Após o início da Guerra Civil (1642) o comércio de vinhos em Inglaterra sofreu fortes restrições. Para tanto contribuíram agravamentos fiscais entretanto introduzidos e a ausência para o exílio de muitos membros da nobility e da gentry, o que fez diminuir consumos. Cromwell, em 1651, procurou fazer renascer a importância da marinha mercante inglesa, colocando-a em concorrência com a holandesa ${ }^{43}$. A aprovação dos "Actos de Navegação" que interditaram o transporte de mercadorias em navios estrangeiros para a Inglaterra e para as colónias britânicas, constituiu um dos esteios dessa política, com reflexos directos no comércio de vinhos. Foram muitas as petições entregues no Parlamento para que os vinhos franceses ficassem fora destas normativas. Em vão, apenas algumas situações pontuais de excepção foram consideradas. Contudo, nos últimos anos mais estáveis do governo de Cromwell, o comércio de vinhos recuperou das quebras anteriores. Ele próprio comprou vinhos franceses, espanhóis e alemães e, alguns embaixadores e nobres que haviam gozado do privilégio de comprar vinhos, viram os seus direitos confirmados. No entanto, o consumo de vinho ficou confinado às classes média e alta da sociedade britânica, cedendo a beberagem de vinho o lugar à da cerveja nos navios da época cromweliana. Os vinhos portugueses, que no reinado de Carlos I chegavam a Inglaterra juntamente com outros produtos como açúcar, sal, tabaco e frutas do sul do país, continuaram a entrar sob a denominação comum aos vinhos de Espanha ${ }^{44}$.

De facto, até meados do século XVII, são muito escassas as notícias de penetração de vinhos portugueses no mercado britânico. Excepção feita aos vinhos da Madeira que já em 1657 tinham alguma expressão (400 toneis chegaram aos portos ingleses nessa ano) e de se saber que, a coberto da designação de vinho espanhol, algum vinho português entrava nas ilhas britânicas ainda no decurso da primeira metade do século, a verdade é que os dados concretos são muito poucos. Só na segunda metade de seiscentos se conhece o frutificar das relações luso-britânicas, também no comércio de vinhos. Mais abundantes são as referências aos vinhos espanhóis em geral e aos vinhos do Sul em particular.

\section{AS FIRMAS INGLESAS DO PORTO E AS SUAS LIGAÇÕES AOS PORTOS ANDALUZES (SÉCULO XVIII)}

Só na segunda metade do século XVII, os vinhos portugueses e em particular os do Porto, lograram ganhar um lugar destacado no mercado britânico. Logo após a adesão de Portugal à Grande Aliança (1703), os ingleses em guerra contra a Espanha e contra a França. Só tinham uma alternativa para se abastecerem de vinho - Portugal e em particular a cidade do Porto, com a qual mantinham relações de intenso comércio desde os tempos medievos. A celebração do tratado de Methuen entre Portugal e a Inglaterra, em Dezembro de 1703, garantiu para além dos tratados que colocaram fim às hostilidades da Guerra da Sucessão de Espanha, a manutenção do comércio vinícola entre os dois países. Por isso, a partir de 1718, estabelece-se na cidade do Porto uma irrequieta comunidade de mercadores

42 FRANCIS, Alan Davis: The Wine Trade, London, 1972, p. 5

43 TREVELYAN, G.M. :História Concisa de Inglaterra, Mem Martins, 1990, II, p. 47.

44 TREVEYLAN, G.M. : História Concisa de Inglaterra, Mem Martins, 1990, II, p. 58. 
britânicos que, encontraram nos vinhos do Douro, uma forte âncora para muitos outros negócios.

Esses mercadores, comercializavam vinhos de proveniência vária. Os livros de Visitas de Saúde às embarcações que entraram na barra do Porto entre 1704 e 1740, dizem-nos que recebiam vinhos de Lisboa e da Figueira, bem como da região da Anadia, da Covilhã, de Viseu, de Setúbal e do Minho, estes últimos conhecidos por vinhos de Viana. Os mesmos mercadores interessaram-se também pelos vinhos do Sul da Península. De facto, com essa origem, passaram na cidade do Porto, onde apenas faziam escala, ou completavam carga, navios fretados por mercadores ingleses do Porto, oriundos dos portos de Alicante, Málaga, Cádiz e Porto de Santa Maria, onde o comércio vinícola conhecia na época forte expressão da presença de britânicos.

Um dos mercadores ingleses radicados no Porto que se interessaram pelo comércio dos vinhos do Sul de Espanha foi Simão Nutte. Trata-se do mercador britânico que entre 1700 e 1756 se manteve durante mais tempo activo em torno do negócio do Vinho do Porto. Instalou-se provisoriamente na Rua Nova, em casa de George Clarck (cônsul no Porto) corria o ano de $1710^{45}$ e até 1721 , permaneceu na mesma morada mas já em instalações próprias, transferindo-se a partir desse ano para Gaia, na outra margem do Douro ${ }^{46}$. Como sucedia em geral com os britânicos do Porto, desenvolveu na cidade uma forte rede de contactos com homens de negócio portugueses, de entre os quais destacamos Manoel Rodrigues Braga que, entre 1710 e 1756, garantiu grande parte das declarações de entrada de vinhos manifestadas por Simão Nutte. Trata-se de um especialista no trato vinícola a partir da cidade do Porto de onde fazia sair vinhos do Douro, mas também os vinhos de Viana, vinhos de Lisboa, vinhos da Anadia e vinhos com a denominação de origem "Serra da Estrela" 47 . Foram os outros ramos de negócio que levaram esta firma inglesa ao contacto com os portos do Sul de Espanha. Do Porto de Málaga, chegou à cidade do Porto em 4 de Setembro de 1730 o navio Ana, carregado de vinhos consignados a este mercador ${ }^{48}$. O navio Knebworth, em 4 de Outubro de 1731, trouxe ao Porto carga de vinhos e passas também com origem em Málaga, destinadas Simão Nutte \& C. ${ }^{449}$ e o mesmo sucedeu mais tarde, em 1736. Em 2 de Maio desse ano, entrou na barra do Douro com "vinho para Inglaterra" um navio igualmente proveniente de Málaga consignado ao mercador inglês ${ }^{50}$.

Este número de ocorrências, embora escasso, é indicador de que a Companhia inglesa do Porto se interessava pelo negócio vinícola em Málaga. E não foi a única. Ricahrd Thompson \& C. ${ }^{\text {a }}$ foi outra das firmas instaladas na cidade do Porto em torno do negócio de vinhos que manteve interesses comerciais no Sul de Espanha. Trata-se uma firma que integra o lote das casas comerciais precursoras das Croft, uma das marcas emblemáticas do Porto. As origens do estabelecimento dos Croft na cidade remonta a 1697 e sabe-se que foram dos primeiros a interessarem-se pelo negócio dos "Red Portugal Wines". Como referimos, também se envolveram no comércio dos vinhos de Málaga. Em 1732, 9 de Setembro, consignado a esta firma entrou a barra do Douro o navio Ana, proveniente de

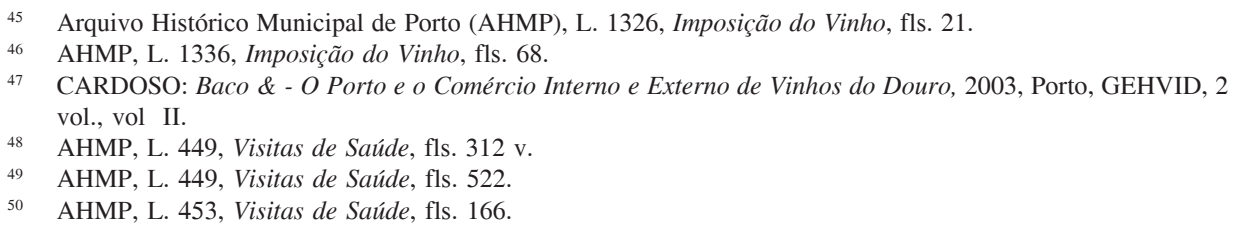


Málaga com carga de vinhos, passas e azeite que seguiram para Inglaterra ${ }^{51}$. Sucedeu o mesmo com o navio Bartolo e Diogo, que entra a 4 de Outubro de $1738^{52}$. No ano seguinte, registamos a entrada do Liborne, em 31 de Janeiro de 1739, também com carga de vinhos consignados à mesma companhia inglesa e com destino às Ilhas Britânicas ${ }^{53}$, sinais muito claros de que algumas das principais firmas que operaram no negócio dos vinhos do Porto já nos inícios do século XVIII, mantinham uma rede de contactos internacionais com base em múltiplos produtos, mas também nos vinhos peninsulares.

A Offley é ainda hoje uma conhecida marca de vinhos do Porto, representada actualmente pelo Grupo Sograp. Trata-se de uma marca com origem em importantes mercadores na City de Londres que visitaram pela primeira vez o Porto em $1761^{54}$. Com toda a probabilidade, a firma foi fundada em $1719^{55}$ por Gregory Bymes, Bymes \& C. ${ }^{\text {a }}$ em 1723 , Bymes \& Hosey em 1729, Bymes \& Talbot em 1747, Henry Bymes em 1756 e Stephenson \& Searle em 1771. William Warthon, gerente da casa Offley \& C. ${ }^{a}$ casou com Francis Stephenson ${ }^{56}$. Foi de resto este o elo de ligação entre estas firmas da primeira metade do século XVIII e a Casa Offley.

Sob a designação social de Henry Bymes \& C. ${ }^{\circ}$, a firma começou a interessar-se também pelos vinhos do Sul de Espanha. De facto, em 1 de Maio de 1733 fez entrar a barra do Douro o navio Joanna, desta vez proveniente de Cádiz, com carga de vinhos para Inglaterra ${ }^{57}$. De resto, as ligações de Henry Bymes \& C. ${ }^{\circ}$ ao porto andaluz estão documentadas nos Livros de Visitas de Saúde às embarcações entradas na barra do Porto desde $1728^{58}$.

O comércio britânico com Viana do Lima, era muito intenso no século XVII ${ }^{59}$ e pelo menos até 1709 o porto desta cidade teve todas as condições para receber embarcações de grande tonelagem. Somente a partir daquela data surgem notícias que se referem ao assoreamento da barra do Rio Lima e à consequente impossibilidade de nela entrarem navios de grande tonelagem ${ }^{60}$. Entre os signatários de um documento redigido nessa altura e que reivindicava obras urgentes de limpeza da Barra do Lima, aparecem Thomas Bearsley e Peter Bearsley. Seguindo John Croft (1788) terá sido este Peter Bearsley o primeiro inglês a interessar-se pelos vinhos do Alto-Douro, era cônsul no Porto Walter Maynard e corria o ano de $1659^{61}$. De facto os primeiros Bearsley ter-se-ão fixado em Viana e Monção e o seu primeiro interesse comercial assentou nas trocas com todo o Alto Minho. Com toda a certeza, os "vinhos de Viana", isto é as produções vinícolas de Monção, e de todo o Vale do Lima, interessaram estes mercadores britânicos. Nada conseguimos saber sobre os seus movimentos de mercadorias, já que o primeiro livro de Visitas de Saúde às

AHMP, L. 450, Visitas de Saúde, fls. 109 v.

AHMP, L. 456, Visitas de Saúde, fls. 135.

AHMP, L. 455, Visitas de Saúde, fls. 44.

SELLERS, Charles ( 142)

SELLERS, Charles, apresenta o ano de 1720 para a fundação desta firma (93). Contudo, já em 1719, Gregory Bymes manifestava vinhos na Imposição do Porto. O nome que consta dos registos é o de Gregório Birne ou Berne. AHMP, L. 1334, Imposição do Vinho, fls. 166. - SELLERS, Charles

SELLERS, Charles ( 93)

AHMP, L. 450, Visitas de Saúde, fls. 290.

AHMP, L. 448, Visitas de Saúde, fls. 273.

SELLERS, Charles ( 126)

BL, Add.20:958, fól. 194.

SELLERS, Charles ( 127) 
embarcações que entraram a barra de Viana, refere-se apenas ao ano de 1708 e encontrase muito incompleto. Mesmo assim, encontramos um registo, datado de 27 de Outubro desse ano, que nos dá notícia de que, consignado a Pedro Bearsley, foi vistoriado o navio Blastont, proveniente de Plymouth, em lastro, com 8 tripulantes a bordo, a indicar que os vinhos seriam carga de retorno a Inglaterra ${ }^{62}$. Do que não temos dúvidas é de que foram estes Bearsley os fundadores da Casa Taylor, uma das mais importantes firmas de vinhos do Porto cuja denominação social subsiste ainda hoje. A primeira firma, Peter Bearsley \& C. ${ }^{\text {, }}$ manteve-se inalterável na sua designação até 1748 e permaneceu desde 1731 negócios com a Andaluzia. Em 17 de Abril desse ano, entrou na barra do Douro o navio Isabel e Maria, proveniente de San Lucar de Sevilha ${ }^{63}$. Em 4 de Junho de 1737 entrou na mesma barra o navio Henrique e Isabel, com carga de vinhos, com origem no porto de Cádiz ${ }^{64}$. No ano seguinte foi a vez do navio Pagy ${ }^{65}$ trazer ao Porto carga de vinhos de Cádiz, consignados ao mesmo mercador.

Outros mercadores de vinho estabelecidos na cidade do Porto no decorrer da primeira metade de setecentos, mantiveram contactos com os portos do Sul de Espanha. Contudo, a avaliar pela carga dos navios que fizeram chegar à cidade oriundos desses portos, o vinho não constituísse mercadoria de grande interesse. A título exemplificativo pode apontarse os casos de John Estevenson \& C. ${ }^{\circ}$ que em 7 de Dezembro de 1734 recebeu a Galera João, com lastro, oriunda de Cádiz ${ }^{66}$. John Page \& C. ${ }^{\circ}$, outro mercador de vinhos do Porto, recebeu do mesmo porto, com carga de carvão, o navio Prestan, em 24 de Fevereiro de $1738^{67}$. John Caullet \& C. ${ }^{\text {a }}$ recebeu o navio Judith em 20 de Março do mesmo ano, também com carga de lastro ${ }^{68}$. Já Sansãom Estuart, recebeu vários fardos de mercadorias que a fonte não especifica e que vieram do porto de Cádiz a si consignadas a bordo do Heathrouth, em 22 de Abril desse ano ${ }^{69}$. Nesse mesmo ano, em 4 de Maio, a Companhia William Pausão, recebeu o navio Samuel e João, em lastro ${ }^{70}$.

\section{A CONCLUIR}

O estudo do comércio mundial dos vinhos peninsulares desde a Idade Média aos alvores do século XIX, passa pelo conhecimento do papel dos ingleses no seu desenvolvimento. De facto, os mercadores britânicos cedo se embrenharam no comércio internacional de tais vinhos e de tal forma que, estamos certos, lhes coube também um papel de relevo na preparação de muitos dos grandes vinhos que hoje se produzem em terras peninsulares. Por exemplo, recentes pesquisas por nós levadas a cabo em arquivos notariais da cidade do Porto, dão conta de que, ao contrário do que se pensava, os ingleses estabelecidos na cidade em torno do comércio vinícola, já no século XVIII, controlavam a produção no Douro. O arrendamento das produções de grandes quintas e de muitas dé-

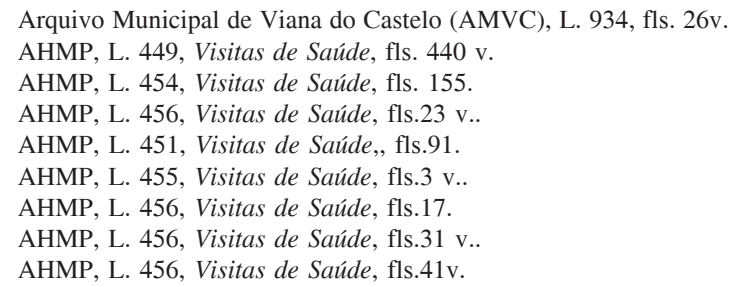


cimas de vinho pagas aos párocos da região, por períodos dilatados de tempo (5 e 10 anos), indicam que tiveram, logo na origem, um papel ainda mal avaliado na preparação dos vinhos do Porto para exportação. Isto não retira mérito nem originalidade às castas, às terras onde se encontram implantadas, às gentes que produziram tais vinhos ao longo dos séculos nas várias regiões vinícolas peninsulares. São conhecidos os méritos autóctones das regiões do Douro, da Madeira, do Marco do Jerez ou de Málaga. Contudo, em nome da verdade histórica, não podemos afastar do contexto da sua evolução o contributo britânico que, pela intensa ligação ao comércio de tais vinhos e pelos elementos aqui adiantados nos parece merecer futura atenção dos estudiosos. Importa pois aprofundar a identificação nominal dos agentes comerciais britânicos nos vários portos do vinho e, a partir desse conhecimento, descendo aos registos oficiais saber mais da sua intervenção nos processos de vinificação. Os elementos aqui adiantados permitem avaliar que boa parte dos que se estabeleceram no Porto, eram agentes multinacionais no negócio de muitas mercadorias e alguns especializaram-se mesmo no comércio internacional do vinho. 